\title{
Projeto Conscientização para Conservação: ações ambientais em unidade de conservação na região do Marajó/PA
}

\author{
Conservation Awareness Project: environmental actions in conservation unit in Marajó/PA region \\ Proyecto de Concientización sobre la conservación: acciones ambientales en la unidad de
} conservación en la región de Marajó/PA

Recebido: 21/01/2022 | Revisado: 29/01/2022 | Aceito: 01/02/2022 | Publicado: 03/02/2022

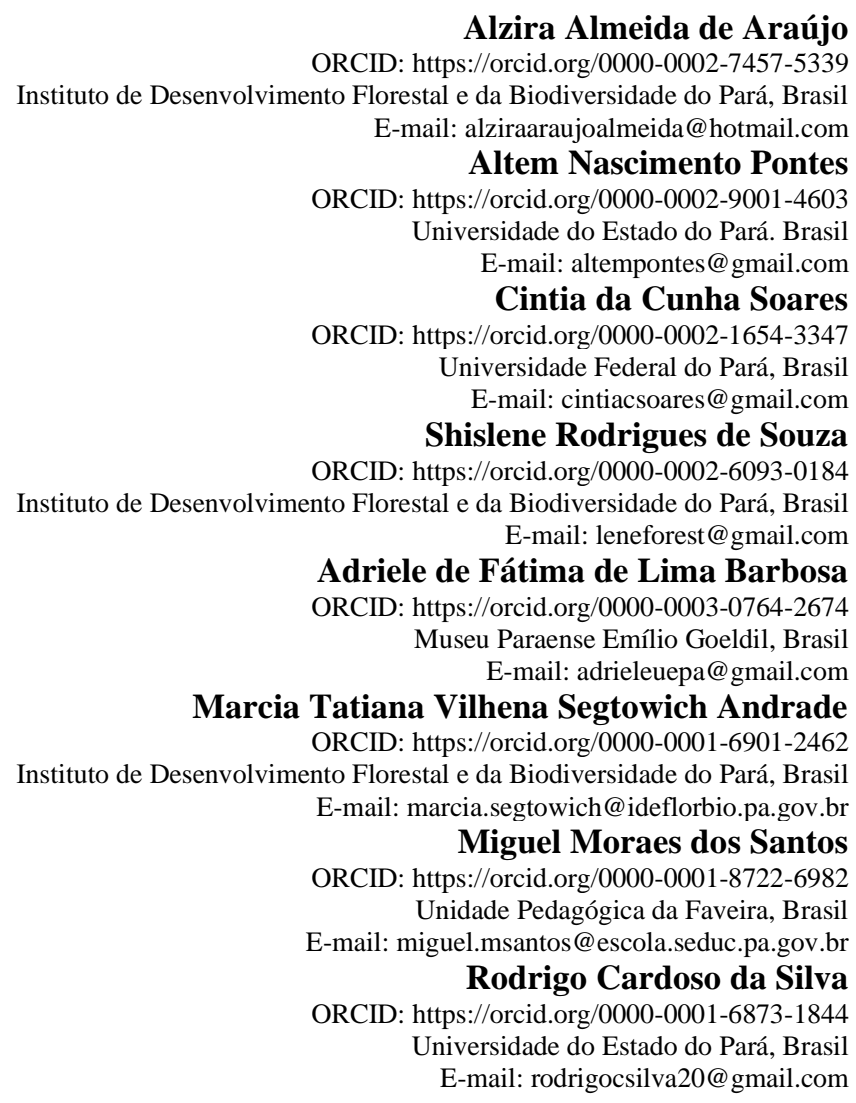

\section{Resumo}

Este trabalho apresenta ações ambientais realizadas do projeto, intitulado, Conscientização para Conservação: Educação Ambiental no Parque Estadual Charapucu, sendo um projeto que surgiu por meio de planejamento de gestão do Instituto de Desenvolvimento Florestal da Biodiversidade do estado do Pará, tendo sua dinâmica pautada em ações que perpassam por comunidades tradicionais em unidade de conservação. O objetivo dar-se em sistematizar as ações que foram realizadas no Parque Estadual Charapucu, sendo uma Unidade de Conservação da Natureza de Proteção Integral localizada na Amazônia Paraense, na Ilha do Marajó, na cidade de Afuá. Metodologicamente essa pesquisa apresenta abrangência qualitativa por envolver estudos de ações sociais grupais, tratando-se de uma pesquisa-ação participativa, o projeto aborda palestras, ações educativas, gincanas, teatro de fantoches, jogos lúdicos pedagógicos, construção de horta suspensa entre outros. Conclui-se com o desenvolvimento do projeto quem vem possibilita alcançar públicos diversos, atualmente foram totalizadas aproximadamente 2.500 pessoas em 15 escolas na zona rural e urbana e 12 comunidades rurais, assim possibilitando trabalhar com escolas e comunidades em área de várzea, sendo um território de difícil acesso onde a exploração dos recursos naturais são a base de sustento das famílias locais. Palavras-chave: Educação ambiental; Parque Estadual Charapucu; Transformação social; Ações educacionais.

\section{Abstract}

This work presents environmental actions carried out in the project, entitled, Conscientization for Conservation: Environmental Education in the Charapucu State Park, being a project that emerged through management planning of 
the Institute for Forestry Development of Biodiversity of the state of Pará, having its dynamics based on actions that permeate traditional communities in a conservation unit. The objective is to systematize the actions that were carried out in the Charapucu State Park, being an Integral Protection Nature Conservation Unit located in the Pará Amazon, on Marajó Island, in the city of Afuá. Methodologically, this research has a qualitative scope because it involves studies of group social actions, in the case of a participatory action research, the project addresses lectures, educational actions, gymkhanas, puppet theater, educational playful games, construction of a suspended vegetable garden, among others. It concludes with the development of the project, which makes it possible to reach different audiences, currently approximately 2,500 people have been totaled in 15 schools in rural and urban areas and 12 rural communities, thus making it possible to work with schools and communities in the floodplain area, being a territory of difficult access where the exploitation of natural resources are the livelihood of local families.

Keywords: Environmental education; Charapucu State Park; Social transformation; Educational actions.

\section{Resumen}

Este trabajo presenta las acciones ambientales realizadas en el proyecto Concientización para la Conservación: Educación Ambiental en el Parque Estadual Charapucu, siendo un proyecto que surgió a través de la planificación de gestión del Instituto de Desarrollo Forestal de la Biodiversidad del estado de Pará, teniendo su dinámica basada en acciones que permean a las comunidades tradicionales en una unidad de conservación. El objetivo es sistematizar las acciones que se realizaron en el Parque Estadual Charapucu, siendo una Unidad de Conservación de la Naturaleza de Protección Integral ubicada en la Amazonía de Pará, en la Isla de Marajó, en la ciudad de Afuá. Metodológicamente, esta investigación tiene un alcance cualitativo porque involucra estudios de acciones sociales grupales, en el caso de una investigación acción participativa, el proyecto aborda conferencias, acciones educativas, gincanas, teatro de títeres, juegos lúdicos educativos, construcción de una huerta suspendida, entre otros. Se concluye con el desarrollo del proyecto, el cual permite llegar a diferentes públicos, actualmente se han totalizado aproximadamente 2500 personas en 15 escuelas de la zona rural y urbana y 12 comunidades rurales, permitiendo así trabajar con las escuelas y comunidades de la zona de llanura aluvial, siendo un territorio de difícil acceso donde la explotación de los recursos naturales son el sustento de las familias locales.

Palabras clave: Educación ambiental; Parque Estatal Charapucu; Transformación social; Acciones educativas.

\section{Introdução}

O projeto Conscientização para Conservação: Educação Ambiental no Parque Estadual Charapucu (PEC) insere-se nas competências de planejamento, ações e práticas de conscientização ambiental das comunidades ribeirinhas da região do Marajó, com o objetivo de desenvolver ações que visem a Educação Ambiental de maneira ampliada e singular às características do lugar. A educação ambiental assume diferentes dimensões para a gestão dos parques, tanto no que concerne a preservação da biodiversidade, quanto à sustentabilidade das suas formas específicas de uso público (Meireles et al., 2018).

Ações educativas são ferramentas importantes para comunicação e busca por soluções de forma participativa, especialmente em áreas protegidas. Ao avaliar a compreensão da comunidade em relação às questões ambientais, identificamse percepções positivas e negativas sobre a prática de manter a integridade do ecossistema, com o papel da educação ambiental de suma importância na perspectiva da inclusão das comunidades do entorno, possuindo o objetivo de fortalecer a efetiva participação democrática e o controle social na gestão daquele espaço protegido (Borges \& Guilherme, 2020).

O desenvolvimento de ações de educação ambiental no entorno e interior do Parque Estadual Charapucu, tornou-se fundamental diante de um cenário territorial de conflito fundiário. O PEC, unidade de conservação com fins de proteção exclusiva, foi criada sobreposta ao Projeto de Assentamento Extrativista (PAE) Ilha Charapucu que permite o uso e manejo dos recursos naturais. As ações foram sendo intensificadas de forma a conscientizar a importância daquela área que não permite uso direto, mesmo que sobreposta a uma área de uso extrativista, por parte das populações ali residentes.

Devido a esta sobreposição territorial, foi celebrado um Termo de Ajustamento de Conduta (TAC) por meio do Ministério Público do Estado do Pará, através da $8^{\text {a }}$ Promotoria de Justiça de Castanhal, entre o Instituto de Desenvolvimento Florestal e da Biodiversidade do Estado do Pará (IDEFLOR-Bio), Instituto Nacional da Colonização e Reforma Agrária (INCRA) e Secretaria do Patrimônio da União (SPU) como compromitentes. O referido TAC tem como objeto assegurar mecanismos de resolução desses conflitos. 
Esse conflito ainda perdura até os dias atuais, e as ações de educação ambiental desenvolvidas na região, contribui efetivamente nas tomadas de decisões sobre a importância de se manter uma unidade de conservação de proteção integral que garanta a proteção de espécies da fauna e flora, e da importância do cuidado do meio ambiente que vise garantir melhor qualidade de vida para as famílias que fazem uso desses recursos.

No PEC existem comunidades, vilas e moradias individuais consolidadas e ocupadas por famílias que utilizam diretamente os recursos naturais para sua alimentação e geração de renda, evidenciando sérios conflitos entre a categoria de UC e os objetivos de conservação da sua criação com os interesses das populações e comunidades tradicionais residentes nessa área. Neste sentido, o projeto de Educação Ambiental foi criado no ano de 2018 para atender estas comunidades tradicionais que vivem na área, com ações que respeitassem suas características e saberes locais.

O objetivo básico do PEC é de preservar os ecossistemas naturais de grande relevância ecológica e beleza cênica, possibilitando a realização de pesquisas científicas e o desenvolvimento de atividades de educação e interpretação ambiental, de recreação em contato com a natureza e de turismo ecológico. Visa também contribuir para a manutenção dos serviços ambientais, bem como garantir os processos ecológicos naturais (Brasil, 2000).

A preservação desses ecossistemas naturais de grande relevância ecológica e beleza cênica, a necessidade de contribuir para a manutenção dos serviços ambientais, bem como garantir os processos ecológicos naturais, não só justificaram a criação da referida UC como são atualmente os grandes desafios enfrentados na gestão do PEC. A gestão também trabalha para gerar conhecimentos ambientais a estas comunidades tradicionais que vivem dos recursos naturais da floresta.

As unidades de conservação, conforme a divisão criada por Milaré (2014.p.1.238) estabelecendo critérios e normas para a criação, implantação e gestão de unidades de conservação, são tidas como espécie de "espaço territorial especialmente protegido" em sentido estrito, entendo aqui a região do PEC como uma unidade de conservação de categoria integral.

De acordo com o Decreto Federal n ${ }^{\circ}$ 6.040/2007, que instituiu a "Política Nacional de Desenvolvimento Sustentável dos Povos e Comunidades Tradicionais" é garantido aos povos e comunidades tradicionais, o acesso aos serviços prestados pelos seus ecossistemas, com o fornecimento dos recursos naturais tradicionalmente utilizados para atender a sua reprodução física, cultural e econômica.

Uma dessas medidas insere-se a efeito do desenvolvimento de ações e práticas de conscientização de Educação Ambiental de maneira ampliada e singular às características das sociedades ribeirinhas marajoaras do PEC e sua zona de amortecimento. Entendendo assim que as atividades comtempladas são direcionadas a educação, no sentindo de dar prioridade a relação de ensino e aprendizagem, pois sendo assim "a educação, qualquer que seja no nível em que se dê, se fará tão mais verdadeira quanto mais estimule o desenvolvimento desta necessidade radical dos seres humanos, e de sua expressividade" (Freire, 1984, p.24), neste sentido a EA vem no sentido de desenvolver as comunidades tradicionais para o pensar ambiental, partindo das realidades.

Não podemos negar que, no discurso, essa racionalidade econômica é favorável ao desenvolvimento sustentável. Ela defende a preservação dos recursos ambientais através da sua valoração e conta com a contribuição da tecnologia para sua exploração. Alguns estudiosos do tema, Guimarães (1998) e Leff (2001), advogam em favor do estabelecimento de uma gestão ambiental que não se limite apenas à regulação do processo econômico, a mercantilização/valoração dos recursos ambientais e a estudos de impactos parciais e desconexos, mas que trabalhe para que o conceito de meio ambiente seja visto em sua amplitude natural, cultura social e política para que toda a sua complexidade comece a ser entendida.

O objetivo deste artigo é apresentar o projeto realizado para desenvolver ações e práticas de conscientização que visem a Educação Ambiental de maneira ampliada e singular às características das sociedades ribeirinhas marajoaras do PEC, na região do Marajó. 


\section{Metodologia}

A área de estudo é o Parque Estadual Charapucu (PEC), criada a partir do Decreto Estadual no 2.592 de 09/11/2010, é uma Unidade de Conservação (UC) de Proteção Integral localizada no município de Afuá, inserida no contexto territorial como a única unidade de proteção integral da Área de Proteção Ambiental (APA) Arquipélago do Marajó, possuindo uma área atual total com forma de um polígono irregular envolvendo uma superfície de 65.181,94 ha e perímetro de 130.070,00 m, conforme indica a Figura 1.

Figura 1. Mapa de localização do Parque Estadual Charapucu.

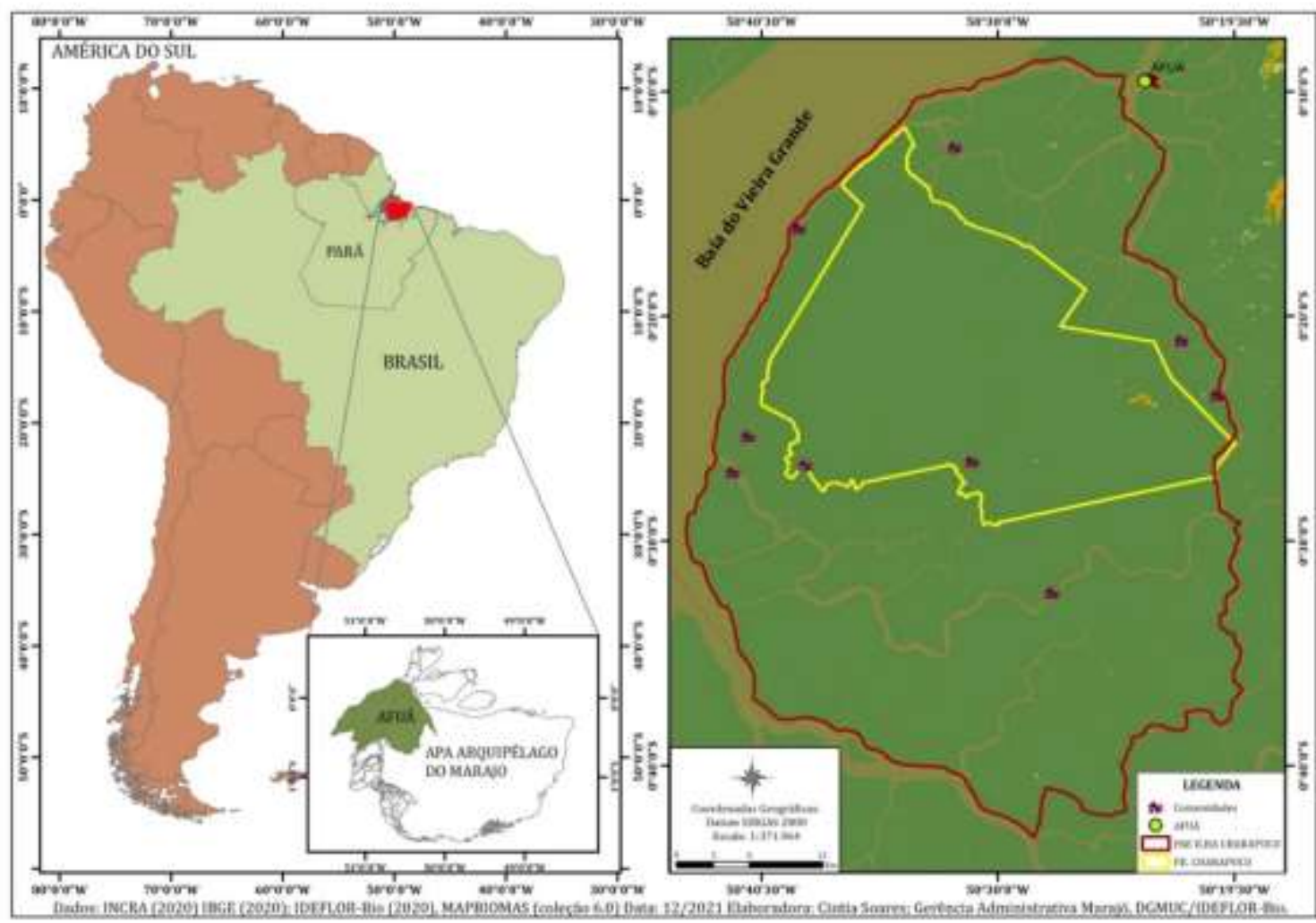

Fonte: Elaborado pelos autores (2022). Dados: INCRA (2020); IDEFLOR-Bio (2020); MAPBIOMAS (coleção 6.0).

A abordagem qualitativa nesta pesquisa buscou explorar subjetivamente os significados das ações decorrentes das ações e experiência de Educação Ambiental, interpretando e contextualizando a realidade de uma comunidade tradicional. Segundo Minayo (2003, p. 21-22) a pesquisa qualitativa está relacionada à questões particulares, trabalhando com o mundo de significados, motivos, aspirações, crenças, valores e atitudes, correspondendo assim a um espaço mais profundo das relações, dos processos e fenômenos que não podem ser limitados à operacionalização das variáveis

A metodologia dar-se pela pesquisa-ação, por evidenciar particularidades e conhecimentos sobre a área e o envolvimento com a prática local através de ações planejadas. Nesse sentido, Silva et al. (2021) afirmam que:

A pesquisa, assim, concretiza-se no próprio processo do fazer investigativo a várias mãos: a dinâmica da pesquisa social campo investigativo pela pesquisa-ação, a superação vivida pelas pessoas da que se volta para a pesquisa - que passam de informantes para atores que fazem parte da pesquisa - por meio de ações efetivas acerca da realidade, do problema e das soluções (Silva et al., 2021, p. 8).

A pesquisa-ação é igualmente discutida em áreas de atuação técnico-organizativa com outros compromissos sociais e ideológicos e dá lugar em sua metodologia a uma diversidade de propostas de pesquisa nos vários campos de atuação 
social, podendo ser aplicada com ações planejadas para impactar no sentido de mudança a realidade vivida, considerando através das políticas públicas e deste referido projeto executado pelo IDEFLOR-Bio, através da Gerência Administrativa da Região do Marajó (GRM).

Sendo uma proposta metodológica na perspectiva do conhecimento e habilidades, a socialização do conhecer e do saber metodológico é absolutamente necessária para que as pessoas participem ativamente. Para decidir e participar com eficácia é necessário estar capacitado. As ações foram realizadas e sistematizadas por relatórios de gestão e planilhas com as atividades e o número de escolas atendidas.

Segundo Angrosino (2009, p. 83), a "[...] observação tem o potencial de produzir novas percepções na medida em que a 'realidade' fica mais nítida em decorrência da experiência em campo". As observações nas ações ambientais foram de estrema importância para análise dos dados, descrever os detalhes das ações para melhor registro das ações, pois o estabelecimento de vínculos com a comunidade é um importante fator na decisão da escolha do campo de pesquisa, e as expectativas em relação às novas descobertas precisam ser autenticas. As suposições podem criar falsas expectativas, por isso devem ser evitadas, assim como devem ser evitadas as monopolizações da atenção do pesquisador (Silva \& Mathias, 2018).

Para Bardin (1977, p.20) "A análise de conteúdo pode ser considerada como um conjunto de técnicas de análise de comunicações, que utiliza procedimentos sistemáticos e objetivos de descrição do conteúdo da mensagem”, tentando buscar padrões ou regularidade nos dados. Composto esta análise de dados, pela sistematização de campo e relatórios para análise do número de pessoas (crianças, jovens e adultos) atendidos, tipo de atividade desenvolvida, e o número de escolas.

Para Almeida e Prandini (2004, p. 78), a "[...] categorização concretiza a imersão do pesquisador em campo e a sua forma particular de agrupá-los segundo a sua compreensão". A comunidade possui seus próprios saberes, sua compressão dos recursos ambientais, e a metodologias das ações são de forma pensada nos costumes locais, tendo assim uma compressão única da realidade. O quadro 1 abaixo lista as comunidades que foram perpassando as ações ambientais, a metodologia das ações:

Quadro 1. Comunidades participantes do projeto.

\begin{tabular}{|l|l|}
\hline COMUNIDADES NO ENTORNO DO PARQUE & RIO/IGARAPÉ/FURO \\
\hline Tabocal & Baía do Vieira Grande \\
\hline Ponta Grossa & Baía do Vieira Grande \\
\hline Nossa Senhora de Fátima & Charapucu \\
\hline Vila dos Crentes & Charapucu \\
\hline Vila Fartura & Charapucu \\
\hline Vila Progresso & Charapucu \\
\hline Nova Jerusalém & Timbó \\
\hline Nova Aliança & Rio Preto \\
\hline Bom Jardim & Gama \\
\hline Nossa Senhora do Perpétuo Socorro & Medonho \\
\hline Jupati & Charapucu \\
\hline Panacalhau & Charapucu \\
\hline
\end{tabular}

Fonte: Elaborado pelos autores (2022).

Utilizamos a EA como linguagem impulsionadora dentro do projeto, denominada como teia ambiental, está é muito utilizada na área da educação, dentro da teia de linguagem para aplicabilidade das ações, a teia metodológica é aplicada para qualquer idade, seguindo este trabalho direcionado a linguagem da natureza e sociedade. Neste sentido, a linguagem da natureza impulsionou as ações desenvolvidas no percurso do projeto, a fim de que as crianças, jovens e adultos e as famílias sejam integradas, inseridas afetivamente de forma que contemple o processo educativo visado pela GRM (Araújo et al., 2021). 
Figura 2. Teia de linguagem, partindo da Linguagem da Natureza e Sociedade.

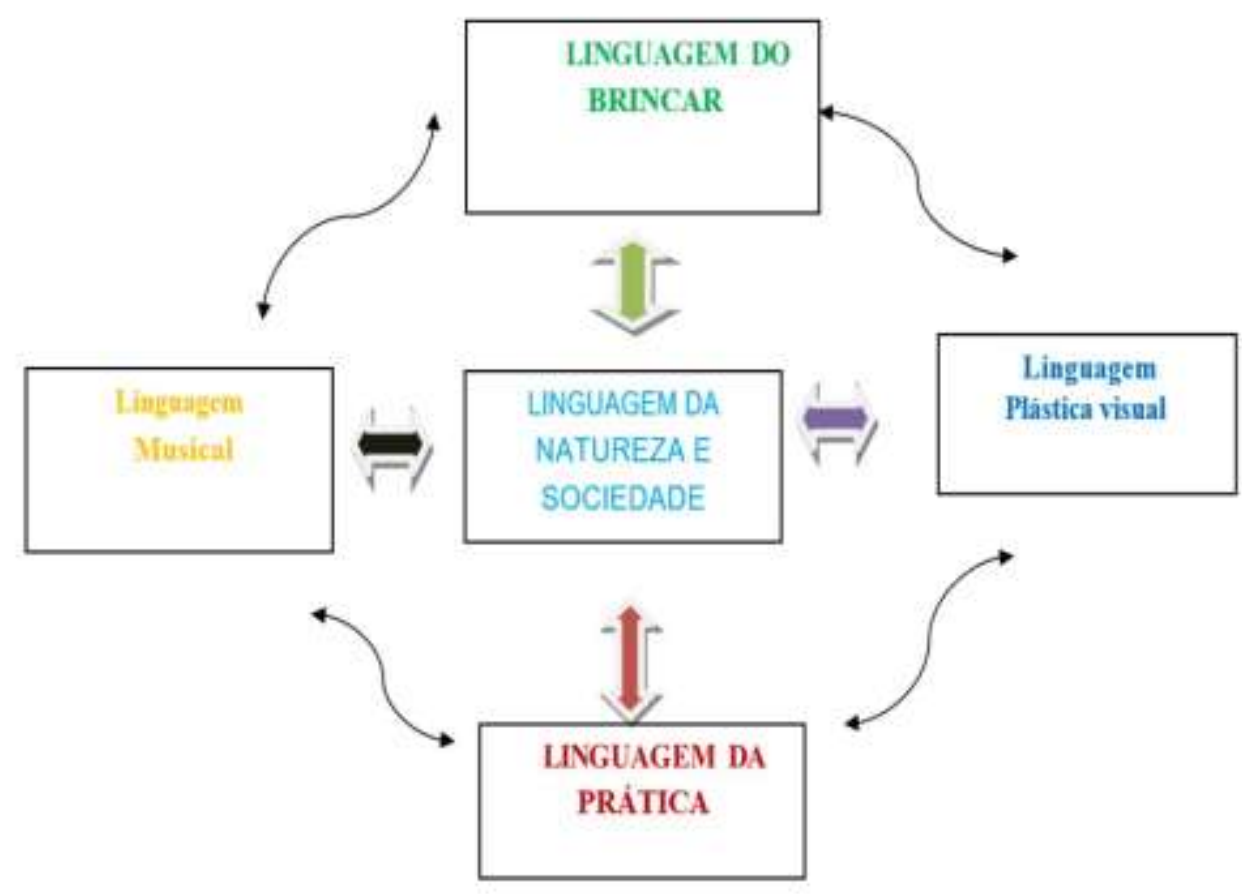

Fonte: Araújo et al. (2021).

Destacando os temas escolhidos para implementação das ações em foco descreve-se cada uma a seguir:

Linguagem Natureza e Sociedade: desenvolve os conteúdos voltados a UC como: observação; percepção visual e auditiva; Brincadeiras ambientais; Identidade; Autonomia; Interação; Formação de conceitos ambientais, Valores humanos; Ideias sustentáveis; Pensamento; Interação; Socialização; aprendizado e construção de horta, palestras e dinâmicas para várias idades, todos voltados para interação a biodiversidade.

Linguagem musical: destinada para trabalhada a contação de história com o teatro de fantoches com encenação teatral que possibilite a manifestação das expressões infantis das crianças, ritmos, percepção auditiva, considerando a linguagem não verbal da natureza como meio de comunicação e interação com o outro, aprende assim de forma didática a história da criação do PEC.

Linguagem plástica visual durante as atividades foi destinada para desenvolver com as crianças do ensino básico a arte livre para criarem e desenvolverem a realidade, criatividade, imaginação, criar e recriar, brincadeiras simbólicas, construção e exploração de materiais de desenhos, pinturas e cor, sempre se remetendo a ideia de natureza.

Linguagem do brincar: capacidade de interação, compreensão de mundo com jogos lúdicos e brincadeiras; expressões de ideias e opiniões, danças, roda de conversa e participação de jogos como meio de resolução de problemas, conceber regras e normas, autonomia, formação de conceitos de identidade.

Percebesse que as atividades de educação ambiental se fazem necessário em sua abordagem o caráter lúdico, haja vista que por meio de atividades dinâmicas a ludicidade surge e contribui para a construção tanto de criança e adultos como um ser social ao qual mostra mais interesse sobre o assunto em questão.

A perspectiva de ambiente como construção de significados e articulação de práticas culturais incorpora o entendimento de que por tratar-se de ambiente construído, não se configura como meramente expressão da natureza, já que está se desdobra nos termos do cultural, numa forma que não é mais a própria formação natural, mais sim o que incorpora 
como significado. Estas valorizam a perspectiva de pensamento, compreensão e valorização da natureza, contextualiza dando a particularidade social do ser humano no caso a cultura afuaense. A EA no caso da Amazônia, diz respeito à forma como o ambiente natural foi assimilado por essa geração de pessoas, por meio da multiplicidade do conhecimento da natureza local.

Neste contexto, foram desenvolvidas as seguintes atividades durante o decorrer do projeto:

1. Contação de História: voltadas para UC e espécies de animais ameaçadas de extinção;

2. Rodas de conversas: palestras com dinâmicas voltadas às questões da natureza, biodiversidade e sustentabilidade para conscientização a partir da EA com jovens e adultos;

3. Dinâmicas em Grupo: palestras desenvolvidas com dinâmicas e brincadeiras, como coleta seletiva, "que animal sou eu" e contação de história;

4. Cinema Ambiental: curta - metragens de EA, desenhos, animações e filmes;

5. Horta suspensa: projeto voltado à para construção de horta suspensa para cultivo de hortaliças para o consumo próprio das famílias;

6. Teatro e arte: apresentação de Teatro de fantoches para educação básica.

\section{Resultados e Discussão}

Ao início de todas as atividades a Unidade de Conservação permeia-se como ponto focal ao decorrer dos planejamentos de todas as metodologias aplicadas nas escolas, desde os problemas que afetam diretamente a vida da comunidade aos projetos que são desenvolvidos pelo órgão gestor de unidades de conservação do Estado do Pará, o IDEFLORBio. A abordagem sobre sustentabilidade por meio de temas transversais como educação ambiental é uma grande aliada na busca por soluções dos problemas socioambientais, sobretudo quando há o envolvimento de atividades lúdicas neste processo (Santagueda et al., 2020).

As comunidades e populações tradicionais muito mais do que "entraves" à criação de unidades de conservação, devem ser valorizadas. Rocha et al. (2015. p.94) afirma "como forma de reverência aos ditames constitucionais da dignidade da pessoa humana e respeito àquelas minorias e culturas que o constituinte colocou em especial guarda", sendo que depois da criação do PEC, muitas histórias foram contadas e recontadas por moradores da própria área, onde identificou-se conversas sobre a criação do parque, e aproveitou-se o momento para uma sensibilização, a partir das reflexões dos próprios alunos e moradores da localidade.

A partir dos problemas apresentados e que afetavam diretamente a vida das comunidades, em sua maioria ligados às práticas de manejo dos recursos naturais, as histórias sobre como as primeiras visitas do órgão no território, permitiram dar a devida atenção às questões de conflito e às questões ambientais, que chamam atenção para quem passa nas pontes e rios da comunidade, e a qualidade da água na região da cidade. Entre os assuntos, salientam-se temas importantes da área como o manejo dos recursos naturais, as espécies do lugar, a proteção da biodiversidade, entre outros.

Serão apresentadas todas as escolas que o projeto passou durante o ano de 2018, descrevendo todas as ações de acordo com a tabela de planejamento da GRM. Atividades aplicadas que passaram por dois momentos.

$\mathrm{Na}$ ação realizada na Escola Municipal Nadir Lobato, o primeiro momento (primeiro dia) foi trabalhado a coleta seletiva e contação de história. No segundo momento (segundo dia) foi trabalhado cinema com Educação Ambiental e contação de história.

Ação foi aplicada em uma área livre com várias turmas. A atividade correspondeu a realidade do município por ter suas questões voltadas aos dejetos orgânicos e não orgânicos, e por ser uma região de várzea, as casas e ruas são cercadas por pontes, onde está mantém acesso e interligação em toda cidade, os mercados, escolas, órgãos públicos, comunidade e periferias se encontram cercados por pontes. 
Com as observações da equipe em campo, percebe-se uma grande concentração de lixo embaixo das casas e pontes, e com isso, verifica-se que a cidade é rodeada por lixeiras, onde por contradição estas não são utilizadas para dejetos simples como saco de pipoca, garrafas plásticas, sacolas plásticas, dentre outros. Para Talles (2002), assim, a característica fundamental da Educação Ambiental está no objeto de estudo o Meio Ambiente, considerando-se seus aspectos físicos, químicos e biológicos, incorporando, também, toda uma rede de relações, culturais, políticas e ecológicas.

O acúmulo de lixo torna-se prejudicial para a cidade e ao PEC, pois com certo período o rio leva, refletindo maior poluição, afetando diretamente e indiretamente a população local pelo mau cheiro, afetando também a questão estética turística, os animais aquáticos e terrestres da região.

As dinâmicas foram para discutir a problemática dos resíduos sólidos na comunidade local e salientar a importância que tem para o entendimento de seus malefícios. A coleta seletiva foi tema focal, mesmo que a cidade não possua meios de coleta seletiva, serviu para entender que a palestra pode servir de referência para a escola, podendo ser um aparato de apoio às famílias que moram na localidade ou nas proximidades do parque, assim também mostrando a importância da separação dos resíduos sólidos. A Figura 3 apresenta as imagens das palestras e atividades de coleta seletiva.

Figura 3. Atividade coleta seletiva A: Escola Municipal Nadir Lobato, Afuá Zona Urbana. B: Escola municipal nadir lobato, Afuá zona urbana.

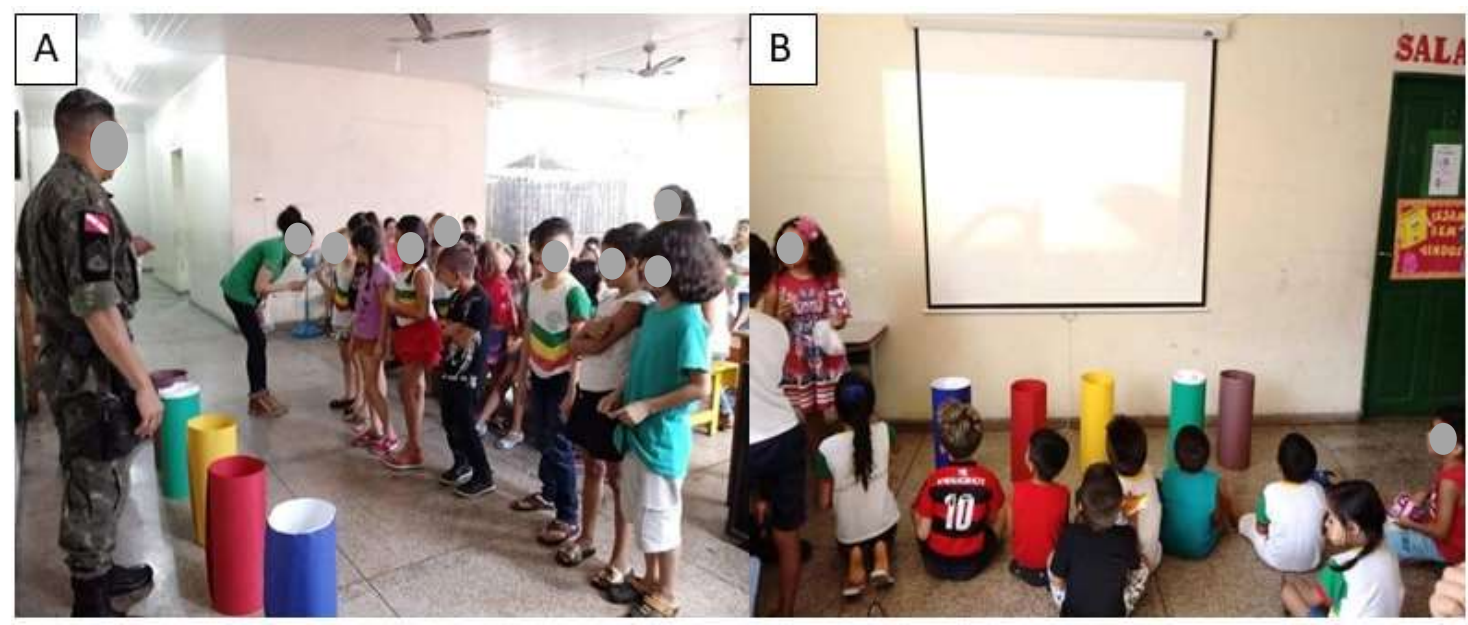

Fonte: Acervo fotográfico dos autores.

Conforme a cor e a composição dos resíduos sólidos, é possível cumprir com papel de cidadão, despejando os resíduos do dia a dia de forma sustentável, e ter mais funcionalidade ao separar o lixo para reciclagem. Na referida escola a contação de história do "coelho e da lebre" foi realizada para fortalecer a relação entre a gestão e a comunidade relacionada às questões do PEC.

O cinema também foi utilizado como um instrumento pedagógico para acompanhar as aprendizagens de Educação Ambiental em UC, destacando o bioma marajoara conforme a realidade regional. A animação passada teve como tema as questões ligadas à natureza e aos resíduos sólidos.

Na Escola Municipal Carlos Rodrigues, a metodologia da contação de história foi muito desenvolvida, sendo aplicada em muitas escolas. No primeiro momento de atividade, fez-se a contação de história "conhecendo os animais da região" e, no segundo momento, onde foi passada a maior parte da história, as marionetes, todas feitas em material de miriti e as técnicas em atuação com o Batalhão de Polícia Ambiental (BPA), se caracterizaram nas falas dos personagens, sendo uma tartaruga, uma graça e um urubu. No decorrer da história abordava-se a questão da natureza, do meio ambiente e da unidade de conservação. 
Mais que isso, essas dinâmicas e concepções socioambientais contestam a ideia de que a biodiversidade seja apenas um produto da própria natureza, sem a intervenção humana. A biodiversidade também é uma construção cultural e social, resultado da ação humana (Santilli, 2005). As crianças se mantiveram motivadas a participar das atividades, incluindo assim elementos formais de jogos como regras, pontuação e até ter alguma premiação, mesmo que simbólica, fazendo com que elas participassem das brincadeiras.

A gincana como instrumento de motivação e aprendizagem foi aplicada como um conjunto de tarefas disputadas entre grupos diversos, com o mesmo objetivo final, aprender sobre Educação Ambiental no lugar onde vivem. As gincanas podem ser realizadas por diversas competições e brincadeiras onde as crianças enfrentam várias provas, com obstáculos que dificultam as tarefas, passando por fases que perpassam pela movimentação corporal à conscientização ambiental.

Na Escola Municipal Manoel Rodrigues Pires, foram atendidas duas turmas com a aplicação do cinema como técnica e estratégia metodológica de criação artística e de informação a respeito da realidade florestal da determinada área de UC. O filme abordado nesta escola teve o caráter de apresentar o que se encontra na natureza para sua preservação.

Com isso, o conhecimento através do cinema, associado a uma metodologia de ensino, podem auxiliar as técnicas no seu uso como recurso didático. Assim, o cinema, em especial o filme "O Lorax em busca da trúfula perdida", pode ser explorado em todos os seus aspectos, e assim deixa de ser um veículo apenas de diversão para assumir o papel de instrumento educativo, que auxilia na construção do saber das sociedades ribeirinhas.

O escopo da introdução dos recursos didáticos na escola é o de criar meios para que o professor divulgue o conhecimento de forma ampla, despertando o interesse e a curiosidade das pessoas que participam. E nisto o cinema pode contribuir, tornando-se um importante aliado nas metodologias com as crianças do PEC.

Na região, por não possuírem energia elétrica na maioria das comunidades pela parte da manhã e pela parte da tarde, consegue-se estimular o interesse ainda maior pelo tema levado sobre a Educação Ambiental. O emprego do cinema ou curta nas escolas não são rotineiras, consegue-se apresentar o cinema como um recurso tecnológico de grande porte e interação, com grande valorização e de muita apreciação para a comunidade escolar, método que para eles se torna inovador.

Diante das observações encontradas acredita-se que o professor deve ser preparado para usar os meios de comunicação como instrumentos de ensino, o motor gerador, por exemplo, serviu como um método apropriado para trabalhar nas escolas ribeirinhas por não possuírem eletricidade durante o dia.

Na Escola Municipal José Reinaldo Homobono, todos os alunos participaram, com as atividades de arte e pintura, com conscientização e roda de conversa sobre a comunidade e seu modo de vida. As crianças se expressarem e falarem sobre o que elas achavam do lugar onde viviam, dos animais, das plantas e dos rios, em seguida, desenvolveu-se a pintura com o desenho da floresta.

No último momento conduziu-se a brincadeira da teia ambiental, fazendo com que os alunos se interajam uns aos outros por meio do novelo, e mostrando que um depende do outro, assim como a natureza depende do ser humano.

As atividades realizadas na escola José Reinado Homobono seguiram com três ações, teatro com fantoches, e "que animal sou eu", além de uma palestra sobre o uso de entorpecentes. A Figura 4 apresenta imagens da escola José Reinaldo Homobono. 
Figura 4. Roda de conversa, arte e educação. A: Escola municipal José Reinaldo Homobono, Afuá zona rural. B: Escola municipal José Reinaldo Homobono, Afuá zona rural.

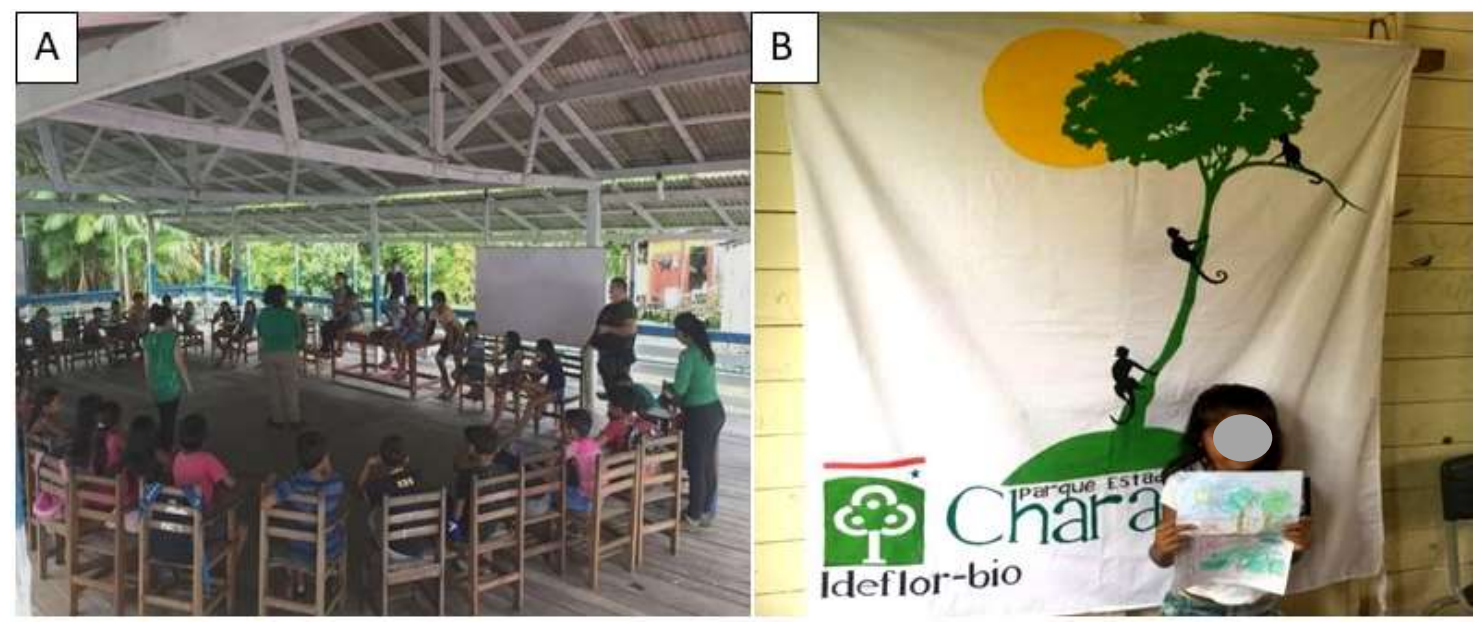

Fonte: Elaborado pelos autores (2018).

Durante as visitas ao campo, circunscritas pelas demandas das atividades de Educação Ambiental na comunidade Nossa Senhora de Fátima, observou-se nas conversas com alunos do ensino fundamental II e em conversas com a comunidade a importância de trabalhar com adolescentes as questões relacionadas às drogas. Pois, o jovem na adolescência formou sua personalidade e individualidade, e é também o período em que as drogas se fazem mais presentes, com isso objetivou-se desenvolver uma análise crítica sobre a necessidade de ações educativas na prevenção do uso de entorpecentes entre adolescentes da comunidade, verificando-se os fatores de risco a eles relacionados.

A palestra de caráter reflexivo-teve direcionamentos relacionados a questões ambientais e de saúde onde se constatou em conversas o tema como prioritário na elaboração das atividades desta comunidade.

A palestra revelou uma associação entre fatores socioeconômicos e o envolvimento familiar como fatores de risco para o consumo de álcool e outras drogas. No caso da comunidade Nossa Senhora de Fátima, foram encontradas vivências relacionadas ao trabalho na mata, em especial o extrativismo, entendendo-se que seja fundamental ajudá-los na vivência dessa fase de transição, destacando a família e a educação como primordiais em suas formações como sujeitos, futuros formadores e conhecedores da área.

A palestra em forma de roda de conversa abordou a classificação das drogas, seus efeitos para quem usa, o que são drogas lícitas e ilícitas, as drogas depressoras do sistema central, o alcoolismo e as drogas estimulantes. Ao final da atividade, foram estimuladas as necessidades que a comunidade tem e seus grandes potenciais naturais, dialogando no propósito que todos fazem parte do processo, dependendo desses recursos naturais de forma saudável, e que o viver bem faz parte da natureza e seus moradores.

E também sendo considerada uma área de proteção ambiental, o Estado deve considerar a comunidade que mora nessas áreas, ao tomar decisões com vista ao seu desenvolvimento e a melhoria das condições de vida da gente marajoara, ressaltando a necessidade de falar sobre as drogas e cuidar do bem-estar dessas comunidades que ali residem.

Na Escola Pastor Crispiano Fernandes de Melo foram aplicadas às ações de teatro com fantoches e jogos lúdicos pedagógicos.

O brincar é fundamental no teatro de fantoches. $\mathrm{O}$ imitar pessoas, animais, situações diferentes, construir sua história de vida e outras pequenas histórias, é participar de atividades de curta duração que envolve o coletivo, e de momentos para pequenas negociações e limites: permitindo-lhe assim, maior descontração e autonomia, pois o brincar: 
Os cursos de formação inicial e continuada incluem em seus currículos a temática do brincar como parte da formação profissional. A presença, nos currículos, de referenciais teóricos que analisam o brincar não é suficiente para alterar a prática pedagógica (Schön, 1990; Zeichner, 1993), que requer o questionamento das ações do cotidiano infantil à luz dos quadros teóricos para reordenar o cotidiano. É necessário analisar o cotidiano dentro de uma pedagogia crítica e ultrapassá-la, buscando uma pedagogia transformadora. As formações inicial e continuada devem incluir brincadeiras como estratégias para iniciar as reflexões. É brincando e pensando sobre o brincar que se adquire consciência sobre sua importância (Kishimoto, 2001, p. 244).

O simples brincar nesta perspectiva das comunidades do Charapucu é de fundamental importância para trabalhar com as crianças das escolas, elas se sentem pertencentes e livres para participar com leveza. Neste sentido, Kishimoto (2001) analisa e comprova que o brincar segue como fundamento principal para trabalhar com materiais lúdicos pedagógicos e suas significações para quem atua com crianças.

A interação desta escola foi de extrema participação das crianças e professores nas atividades, por esta escola comportar o ensino fundamental I pela parte da manhã, os alunos foram muito participativos nas atividades, principalmente em relação aos jogos lúdicos pedagógicos. Foram distribuídos grupos de no máximo 10 alunos para cada círculo, em seguida, foram distribuídos 5 jogos cada um contemplando a faixa etária das crianças. A Figura 5 apresenta imagens das atividades realizadas na escola Pastor Crispiniano Fernandes de Melo.

Figura 5. Escola Pastor Crispiniano Fernandes de Melo. A: Quebra - cabeça. B: Equipe de apoio.

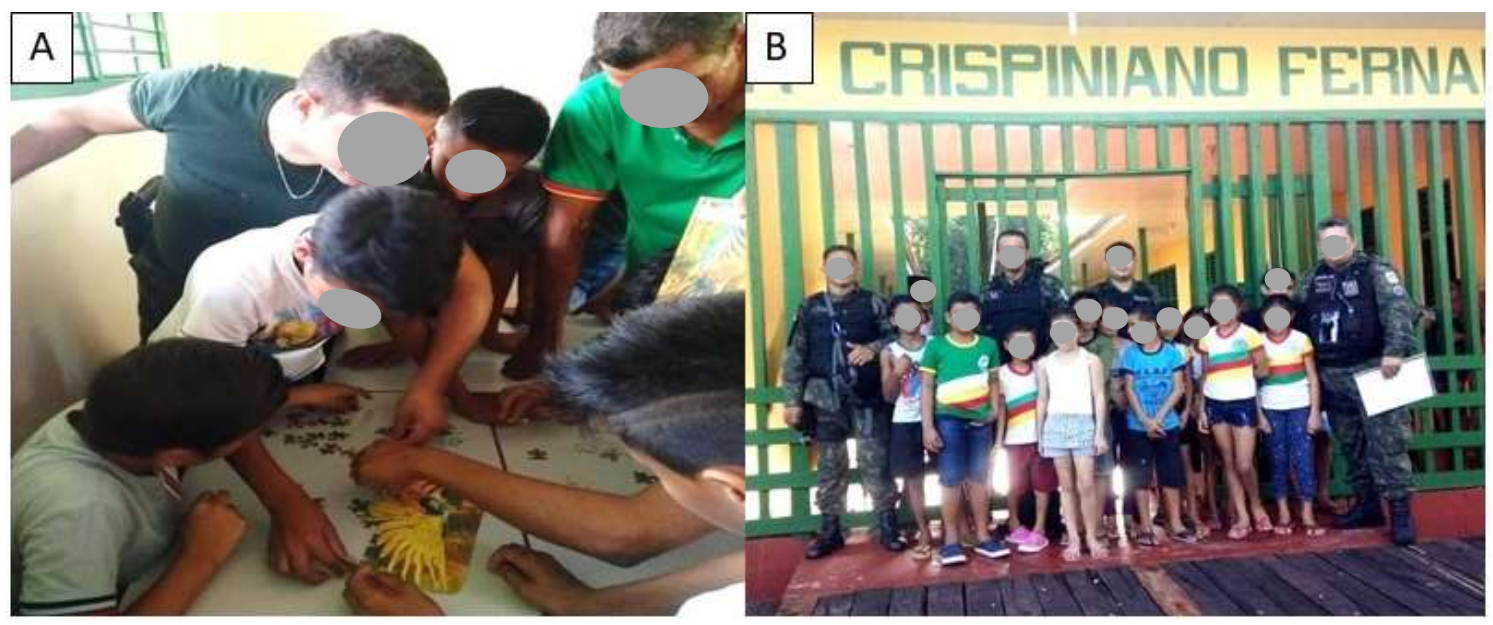

Fonte: Elaborado pelos autores (2018).

No final do processo de aplicação das atividades, dialogou-se e perguntou-se o que chamou a atenção sobre o aprendizado dos jogos, foram lembrados sobre os animais que possuem na região, o destino do lixo, e sua parte para ajudar, considerando a singularidade das crianças bem pequenas em sua importância de cuidado. A atividade das crianças com os jogos lúdicos pedagógicos torna-se, assim, fundamental na construção do conhecimento.

A aplicabilidade das ações na escola Pastor Crispiano Fernandes de Melo foi de participação total dos alunos, por ser uma escola localizada ao entorno do parque que comporta pequena quantidade de alunos em relação a outras escolas trabalhadas, tendo assim um cuidado maior, dando a oportunidade de que cada criança fosse contemplada com total sucesso nas atividades e que todos pudessem participar.

A atração principal neste dia foi voltada à palestra e brincadeira com os jogos pedagógicos da coleta seletiva, o jogo foi escolhido para tratar sobre o potencial de limpeza que a escola verticaliza.

A exemplo, menciona-se o momento em sala de aula ao qual se salienta que os alunos devem jogar o lixo no seu local determinado e não pela janela de sala de aula, onde cada participante tinha direito a um objeto na carta e teria que colocar em 
sua cor correspondente da coleta seletiva, assim pontos fundamentais desta atividade foram falados em relação aos resíduos sólidos, a classificação dos resíduos sólidos, o que pode e o que não pode ser reaproveitado, demonstração de imagens onde os animais são afetados diretamente pela produção do lixo.

As crianças brincam nas árvores, fazem balanços com cipós, nadam nos rios, mas também brincam com bonecas e assistem à televisão. Para aproveitar essa vivência, é preciso colocar na instituição infantil brinquedo com troncos de árvores. As brincadeiras da comunidade estimulam a emergência do letramento ambiental, quando a criança "conta" quantos cachos de açaí tirou.

Segundo Kishimoto (1999), o ato de brincar estimula a concentração, a paciência, o trabalho em equipe, o respeito por regras e outros benefícios. As crianças que vivem na zona rural têm experiências diferentes das que moram na cidade. Vivem em contato direto com a natureza, em florestas ou matas, junto a rios ou campos. E por atividades lúdicas, essas características são efetivadas proporcionando um conhecimento significativo em relação a diversos assuntos.

Com isso, as brincadeiras com as crianças aconteceram de forma que abrangessem sua vida local, as contações de histórias regionais, as brincadeiras ao ar livre. É uma situação importante vivenciada pelas crianças e este exercício lúdico proporciona descobertas de novos conhecimentos e desenvolvimento de muitas habilidades de forma natural e agradável. Ao brincarem, as crianças estão mais aptas a desenvolverem bons sentimentos, partilharem, socializarem-se, respeitarem-se mutuamente.

A ludicidade faz parte do cotidiano de qualquer criança, pois auxilia no imaginário infantil e por meio dele representa a realidade que conhece. O lúdico, vivenciado por brincadeiras e várias outras atividades, possibilita a criança entender o seu mundo, facilitando a compreensão do conhecimento infantil, pois as atividades lúdicas, os brinquedos e brincadeiras podem desenvolver a criança em todos os aspectos, e isso inclui afetivo, cognitivo, físico e social.

A aplicabilidade das atividades na Escola Eleodoro dos Santos Fonseca localizada no rio São Domingos na comunidade Nossa Senhora de Nazaré, e no Centro Educacional Infantil Treopompo Nery foram os jogos lúdicos pedagógicos e o teatro com fantoches que serviram como ponto focal nestas comunidades.

$\mathrm{O}$ teatro de formas de animais e pessoas, uma chamada de Flora e a outra de Bio, fazem a apresentação da história criada para apresentar o PEC, onde se teve a participação de cada pessoa imitando um animal, pois o teatro é um instrumento que transmite alegria e conhecimento. Esta metodologia está presente desde os primórdios da humanidade, quando os homens utilizavam objetos e partes do seu corpo para criarem formas através das sombras projetadas em alguma superfície e ali contarem histórias para os demais. Além disso, o teatro de fantoches sempre esteve presente nas manifestações culturais de vários povos desde a antiguidade, conforme Figura 6. 
Figura 6. Atividade de fantoche. A: Escola Eleodoro dos Santos Fonseca. B: Escola Centro Educacional Infantil Treopompo.

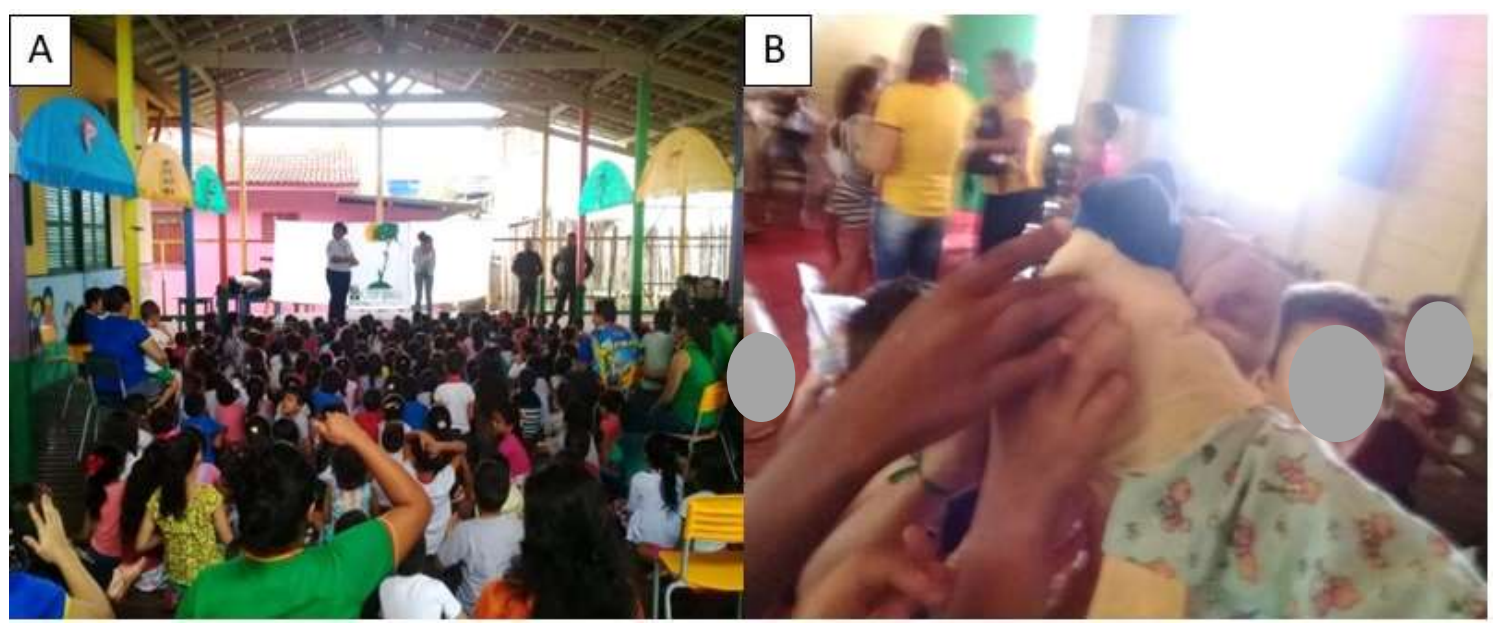

Fonte: Elaborado pelos autores (2018).

Constata-se que os alunos ainda não haviam tido contato com a obra teatral. Os únicos referenciais que elas tinham estavam ligados à linguagem televisiva. Desse modo, decidimos fazer a contação da história com teatro de fantoches, com muito sucesso desta atividade essas crianças costumavam gritar para se comunicarem. No entanto, observou-se que, durante a fala dos animais, elas conseguiam deixar o som ecoar sobre o lugar e ficaram mais atentas.

As duas oportunidades que tivemos de levar o teatro de fantoches para essas crianças assistirem foram muito válidas. As crianças mantiveram-se muito atentas durante as apresentações e compreenderam todas as temáticas sobre a natureza e a criação do PEC. Além disso, tiveram a oportunidade de brincar com os fantoches e conhecer que atrás da cortina quem fazia a fala do personagem, aproveitaram para conhecer os bastidores do fazer teatral de fantoches. Muitas crianças se encantaram pela personagem do Bio, chamavam a todo momento "Bio, cadê você Bio".

É importante salientar que nossas atividades foram adaptadas ao espaço e à realidade escolar que se encontrou pelos caminhos, seja na zona urbana ou na zona rural de Afuá, passando por diversas comunidades ribeirinhas. No entanto, acreditase que a comunidade escolar também teve sua porta aberta ao ser preparada para receber as atividades de EA.

\section{Considerações Finais}

Com as ações para orientar e desenvolver uma sociedade fundada em bases ecológicas, equidade social, diversidade cultural e democracia participativa tende a estabelecer o direito à Educação Ambiental, a trabalhar com escolas e comunidades tradicionais à capacitação e à formação ambiental como fundamento da sustentabilidade e para preservação da biodiversidade.

As ações permitiram a cada grupo social produzir e apropriar-se de saberes, técnicas e conhecimentos para participar nos processos de gestão do território. Portanto, propiciar esses grupos a decidir sobre suas condições de existência e definir sua qualidade de vida contribui para a ruptura da dependência e redução das iniquidades fundadas na distribuição desigual do conhecimento, além de promover um processo onde os cidadãos e comunidades possam intervir a partir de seus saberes e capacidades próprias nos processos de decisão e na gestão do território.

A realização deste trabalho na região do PEC dialogou com as comunidades tradicionais e efetivou uma gestão mais participativa, ampliando e fortalecendo parcerias institucionais e construindo um cenário futuro direcionado à conscientização à Educação Ambiental.

Durante a execução do projeto, possibilitou-se alcançar crianças, jovens e adultos, totalizando 2.700 pessoas em 15 escolas na zona rural e urbana, 12 comunidades rurais e 1 ONG Missão de Assistência ao Cuidador - MAC que se situa no 
bairro periférico do município de Afuá/PA.

Mesmo com o aumento de pesquisas que chamam a atenção para a realização de ações ambientais, raramente encontramos documentos de suporte que trabalhem com esta região do marajó. A discussão levantada sobre estas ações, alerta para a urgência de ser trabalhada esta região do Charapucu. A proposta trazida é a de que educadores e gestores de diferentes áreas criem estratégias que contribuam para composição da educação ambiental em áreas de unidade de conservação estaduais, principalmente em área de várzea tornando-a sustentável para uma região que possui índices de pobreza muito altos.

\section{Referências}

Almeida, L. R. de \& Prandini, R. C. A. R. (2004). A entrevista na educação: a prática reflexiva. (4a ed.). Líber Livro Editora.

Angrosino, M. (2009). Etnografia e observação participante. Artmed.

Araujo, A. A. de, Pontes, A. N., Quaresma, A. P., Souza, S. R. de, Barbosa, A. de F de L., Santos, M. M dos, Santos, B. M dos \& Nascimento, D. de S. V. Por entre as várzeas da Amazônia: educação ambiental como instrumento de gestão no Parque Estadual do Charapucu/ Marajó-PA. Brazilian Journal of Development, 7 (11), 102957 -102974. https://doi.org/10.34117/bjdv7n11-086

Bardin, L.(1977). Análise de Conteúdo. Edições 70.

Borges, P. de G. \& Guilherme, F. A. G. (2020). Educação ambiental: a chave da mitigação de conflitos e proteção de unidades de conservação no cerrado. Geoambiente On-Line, (37), 126-145. https://doi.org/10.5216/revgeoamb.vi37.63214

Brasil (1988). Constituição da República Federativa do Brasil de 1988. http://www.planalto.gov.br/ccivil_03/constituicao/constituicao.htm

Brasil (1999). Lei $n^{\circ}$ 9.795, de 27 de abril de 1999. Dispõe sobre a educação ambiental, institui a Política Nacional de Educação Ambiental e dá outras providências. http://www.planalto.gov.br/ccivil_03/leis/19795.htm

Brasil (2000). Lei $n^{\circ}$ 9.985, de 18 de julho de 2000. Institui o Sistema Nacional de Unidades de Conservação da Natureza e dá outras providências. http://www.planalto.gov.br/ccivil_03/leis/19985.htm

Brasil (2002). Decreto Federal n ${ }^{\circ} 4.340$, de 22 de agosto de 2002. Regulamenta artigos da Lei no 9.985, de 18 de julho de 2000 , que dispõe sobre o Sistema Nacional de Unidades de Conservação da Natureza - SNUC, e dá outras providências. http://www.planalto.gov.br/ccivil_03/decreto/2002/d4340.htm

Brasil (2007). Decreto Federal n ${ }^{\circ}$ 6.040, de 07 de fevereiro de 2007. Institui a Política Nacional de Desenvolvimento Sustentável dos Povos e Comunidades Tradicionais. http://www.planalto.gov.br/ccivil_03/_ato2007-2010/2007/decreto/d6040.htm

Freire, P. (1984). Ação cultural para liberdade outros escritos. (7a ed). Paz e terra.

Guimarães, R.P. (1998). Modernidad, médio ambiente y ética: un nuevo paradigma de desarrollo. Ambiente e Sociedade, 1 (2), 5-24.

Ideflor-Bio (2010). Parque Estadual Charapucu. Instituto de Desenvolvimento Florestal e da Biodiversidade do Estado do Pará. https://ideflorbio.pa.gov.br/unidades-de-conservacao/regiao-administrativa-marajo/parque-estadual-charapucu/.

Kishimoto, T. M. (1999). Jogos Infantis: O jogo, a criança e a educação. (6a ed.). Vozes.

Kishimoto, T. M. (2001) Brinquedos e materiais pedagógicos nas escolas infantis. Educação e Pesquisa, 27(2), 229-245. https://doi.org/10.1590/S151797022001000200003

Leff, E. (2001). Saber ambiental: Sustentabilidade, racionalidade, complexidade, poder. (2a. ed.). Vozes.

Meireles, C. P., Santos, D. C. R dos \& Pimentel, D. de S. (2018). Caminhos para a educação ambiental em parques. Revista Eletrônica Uso Público em Unidades de Conservação. 6 (10). http://www.periodicos.uff.br/uso_publico

Minayo, M. C. de S. (2003). Pesquisa Social. (22a ed). Vozes.

Milaré, E. (2014). Direito do Ambiente. (9a. ed). Revista dos Tribunais.

PARÁ (2010). Decreto $\mathrm{n}^{\circ}$ 2.592, de 09 de novembro de 2010. Cria o Parque Estadual Charapucu no Município de Afuá, e dá outras providências. https://www.sistemas.pa.gov.br/sisleis/legislacao/1472

Rocha, I., Treccani, G., Benatti, J. H., Haber, L. \& Chaves, R. A. F. (2015). Manual de direito agrário e ambiental: Lições de Direito Agroambiental. (2a ed.). Fórum.

Santilli, J. (2005). Sociambientalismo e novos direitos. Peirópolis.

Santagueda, V. M. P, Cantalice, A. da S., Silva, A. B. da, \& Mafort, M. E. (2020). Comportamento sustentável: promoção da consciência ambiental através da gincana. Pesquisa, Sociedade e Desenvolvimento, 9 (2), e177921976. https://doi.org/10.33448/rsd-v9i2.1976

Silva, M. G. (2007). Práticas educativas ambientais, saberes e modos de vida locais. Revista COCAR, 1, 47-57. https://periodicos.uepa.br/index.php/cocar/article/view/142 
Research, Society and Development, v. 11, n. 2, e48411226038, 2022

(CC BY 4.0) | ISSN 2525-3409 | DOI: http://dx.doi.org/10.33448/rsd-v11i2.26038

Silva, P. R. S. \& Mathias, M. S. (2018). A etnografia e observação participante na pesquisa qualitativa. Ensaios Pedagógicos, 2 (1), 54-61. http://www.ensaiospedagogicos.ufscar.br/index.php/ENP/article/view/65

Silva, A. L., Matias, J. C. \& Barros, J. A. (2021). Pesquisa em Educação por meio da pesquisa ação. Revista Pesquiseduca, 13 (30), $490-508$. https://periodicos.unisantos.br/pesquiseduca/article/view/1060/938. 